\title{
Sex and Drugs and Rock and Roll
}

\section{Erhard Taverna}

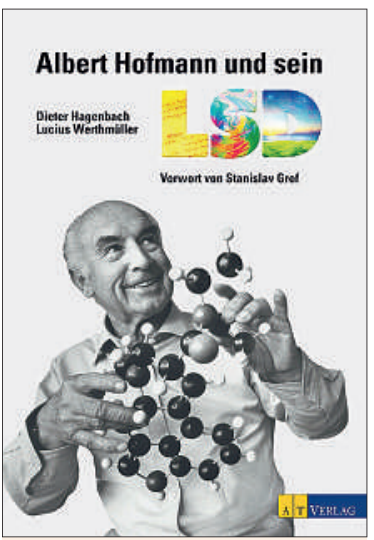

Dieter Hagenbach, Lucius Werthmüller Albert Hofmann und sein LSD

Aarau: AT Verlag; 2011 250 Seiten. $49.90 \mathrm{CHF}$ ISBN 978-3-0380-0530-8
«Albert Hofmann und sein LSD» lautet der Titel eines umfangreichen Werkes der Autoren Dieter Hagenbach und Lucius Werthmüller. Das Buch ist Biographie, Firmengeschichte, Zeitchronik und Kompendium der Halluzinogene in einem, gut erzählt, gründlich dokumentiert und reich bebildert.

Albert Hofmann (1906-2008) studierte nach einer kaufmännischen Lehre organische Chemie an der Universität Zürich und begann nach dem Doktorat seine Arbeit bei der Sandoz in Basel. Die für ihre Farbstoffe bekannte Firma investierte in ein Forschungsprogramm zur Analyse und Synthese von Wirkstoffen aus Heilpflanzen. Hofmann erforschte die Meerzwiebel (Scilla maritima), den Fingerhut (Digitalis purpurea, lanata), danach die Alkaloide des Mutterkorns aus dem parasitären Fadenpilz Claviceps purpurea. Aus dem Grundbaustein Lysergsäure, deren Struktur erstmals 1934 in den USA geklärt wurde, stellte Hofmann viele Derivate her. Das Lysergsäurediäthylamid (LSD) war als Analogon zum bekannten Kreislaufmittel Coramin gedacht, verlor aber für einige Jahre, nach enttäuschenden Tierversuchen, das Interesse der Mediziner und Pharmakologen. Bei der zweiten Synthese 1943 kam es zum ersten, unbeabsichtigten Kontakt mit der Substanz, der zu einer Reihe von Selbstversuchen führte, die das Laborjournal und ergänzende Berichte minutiös festhalten. Hofmanns spektakuläre Fahrradtour vom Fabrikgelände durch die Aussenbezirke Basels zu seinem Haus wurde später zur Legende. Zu den 40er Jahren gehört auch die Entdeckung der Tranquilizer, eine Art Gegenpol zum LSD. Seine langjährige Grundlagenforschung führte zu Arzneimitteln wie Methergin, Hydergin, Dihydergot und Bromokriptin, was der Sandoz Umsätze in Milliardenhöhe bescherte. Hofmann, der als Vater des LSD weltbekannt wurde, bezeichnete den Pilz als Mutter, die ihm einige pharmazeutische Kinder geboren habe: «Während nun das Methergin dabei hilft, leibliche Kinder zu gebären, erweist sich das LSD als sehr hilfreich bei der Geburt des spirituellen Kindes, das in jedem Menschen schlummert.» 1947 wurde der erste Bericht über systematische Versuche am Menschen im «Schweizer Archiv für Neurologie und Psychiatrie (Stoll)» publiziert. Sehr schnell fand der Stoff als Hilfsmittel eine zunehmende Verbreitung auch in England, in den USA und in der Sowjetunion. 1964 wurde LSD in 18 europäischen Behandlungszentren und von vielen ambulanten Psychotherapeuten regelmässig angewendet.

Das Buch beschreibt zwei Welten, die nicht verschiedener sein könnten. Die eine ist die des Mili- tärs und der Geheimdienste, die in Zeiten des Kalten Krieges mit dem neuen Wirkstoff experimentierten. Unter zahlreichen Codenamen der CIA, wie Bluebird und MK-Ultra, wurden unglaublich menschenverachtende Versuche mit tatkräftiger Hilfe von Ärzten, darunter ehemalige Naziwissenschaftler, durchgeführt. 1953 schloss die Sandoz mit den USA einen Vertrag über wöchentliche Lieferungen von hundert Gramm LSD mit der Zusicherung, die kommunistischen Staaten nicht zu beliefern. In der Folge wurden die Tschechen zu den grössten LSD-Produzenten weltweit. Von ihnen bezog der KGB seine Rationen, die er in russischen Kliniken, Gulags und Kasernen erprobte, und über die DDR fand das LSD schliesslich den Weg in den westlichen Untergrund.

LSD war aber auch der Treibstoff einer friedlichen Kulturrevolution der 60er Jahre. Die Chemieproduktion im Untergrund führte zur rapiden Verbreitung des nach wie vor legalen Halluzinogens, vor allem in den USA. Die psychedelisch inspirierte Gegenkultur der Studenten, Hippies, Künstler und Vietnamkriegs-Gegner forderte das etablierte Bürgertum heraus. Parolen wie «Blumen im Haar, Liebe im Herz und LSD im Hirn» oder «Sex and Drugs and Rock and Roll» befeuerten die junge Generation. Zum Sound der Sixties gehörten Jimi Hendrix, die Beatles und Pink Floyd, Aldous Huxley, Timothy Leary, Carlos Castaneda und unzählige andere. Das Abschieben halluzinogener Substanzen in die Illegalität verlief in Raten, bis zum völligen Verbot 1966 in ganz Amerika. Nachdem der repressive Staat an der Droge nicht mehr interessiert war, wurde die Substanz auch für Forschungszwecke geächtet. Die Herstellung wurde verboten, Zuwiderhandlung drakonisch bestraft, der Gebrauch dämonisiert, und die verbliebenen Propheten der Alternativkultur wurden verfolgt. Zeitlebens hatte Albert Hofmann intensiven Kontakt mit unzähligen Menschen, die von der bewusstseinserweiternden Wirkung des LSD überzeugt waren und zum Teil gemeinsam mit ihm Versuche durchführten. Die lange Liste prominenter Namen liest sich wie ein «Who is Who» der letzten Jahrzehnte.

Der Sound ist schon lange verstummt. Die wilden Jahre erscheinen aus heutiger Sicht wie ein Märchen aus längst vergangenen Zeiten. Doch Albert Hofmann ist bis heute in der Öffentlichkeit der bekannteste Chemiker des 20. Jahrhunderts geblieben. Aus seinem Sorgenkind LSD wird vielleicht doch noch die erwünschte Wunderdroge. Neue Studien auf dem Felde der Psychiatrie und Neurologie sind in zahlreichen Ländern wieder zugelassen. 